\title{
Rancang Bangun Voice Recognition Untuk Aktifasi Mobil Menggunakan Handphone
}

\author{
Ridha Alfian, Novi Azman \\ Program Studi Teknik Elektro, Fakultas Teknik dan Sains, Universitas Nasional \\ Korespondensi : novi_azman@yahoo.com
}

\begin{abstract}
ABSTRAK. Perkembangan dalam bidang teknologi elektronik, telekomunikasi, dan automotif pada saat ini bisa terbilang cukup pesat dan mendapatkan perhatian dari masyarakat luas, salah satunya adalah sistem untuk aktifasi mobil dari jarak jauh.Sistem ini mengenali voice pemilik mobil melalui media handphone dengan cara menelepon perangkat hardware yang terdapat pada mobil yang berfungsi sebagai penerima suara pemilik mobil untuk digunakan sebagai kata kunci untuk aktifasi mobil. Ketika mobil ingin dinyalakan, mobil memerlukan kata kunci berupa kode suara agar bisa aktif. Pada saat terjadi tindakan dibuka secara paksa pada perangkat mobil, mobil tersebut akan merespon untuk menelepon pemilik sebagai peringatan tanda bahaya, sehingga pemilik memiliki respon yang cepat untuk memerintahkan mobil yang terhubung dengan mikrokontroller yang berfungsi menonaktifkan mesin pada mobil sehingga mobil tidak dapat dicuri oleh orang lain. Pada perancangan sistem ini menggunakan mikrokontroller Arduino dengan seluruh perangkat pada sistem aplikasi keamanan yang terintegrasi dengan modem GSM dan modul EasyVR.
\end{abstract}

Kata Kunci: Voice Recognition, Modem GSM, Mobil

\begin{abstract}
Developments in the field of electronic technology, telecommunications, and automotive at this time can be quite fast and get the attention of the general public, one of which is a system for remote activation of the car. This system recognizes voice car owners through mobile media in a way to call hardware devices available in the car that serves as asound receiver car owner stouse as keywords for the activation of the car. When cars want turned on, the car requires a code keywords voice to be active. In the event the action is opened by force on the car, the car will respond to call owner as a warning ign of danger, so the owners have a fast response to command the car connected to the microcontroller which serves to disable the enginein the car so that the car can not be stolen by others. In designing this system uses an Arduino microcontroller with all devices on the system security application integrated with a GSM modem and module EasyVR.
\end{abstract}

Keywords: Voice Recognition, modem GSM, Car

\section{PENDAHULUAN}

Perkembangan yang sangat pesat dibidang teknologi, baik itu telekomunikasi maupun dalam hal transportasi telah menghasilkan berbagai sistem, aplikasi atau peralatan yang canggih dan cerdas yang merubah kehidupan manusia pada saat ini dan masa yang akan datang. Salah satu teknologi transportasi yang saat ini banyak digunakan pada perkotaan adalah sebuah mobil, karena memiliki daya tempuh yang jauh dan memiliki kapasitas yang cukup besar. Dengan melihat kondisi naiknya tingkat permintaan dan peminatan terhadap kendaran roda empat yang berfungsi sebagai alat transportasi yang nyaman dan aman, para produsen di paksa untuk membuat mobil dengan tingkat kenyamanan dan keamanan yang tinggi untuk dikendarai dan dipergunakan. Salah satu yang memicu hal tersebut adalah tingkat kelalaian pemilik yang terkadang lupa mengkunci pintu atau mudahnya mobil untuk dirusak sistem kemanannya sehingga si pemilik mobil terkadang marasa tidak aman dan nyaman ketika meninggalkan mobilnya. Untuk memecahkan masalah tersebut diatas, maka dirancanglah suatu sistemaktifasi suara pada mobil kelas premium yang dapat di kendalikan dari jarak jauh dengan menggunakan media handphone pada mobil kelas premium saat iniyang memiliki tingkat keamanan khusus (private car) yang bertujuan untuk meminimalisir tingkat kelalaian pemilik ataupun dari tindakan pencurian pada kendaraan. Sistem ini terjadi bila pintu mobil dan kunci kontak mobil tidak digunakan secara benar. Sistem aktifasi ini diterapkan dengan menggunakan suara sebagai fungsi aktifasi dan juga keamanan yang dikontrol oleh 
handphone dengan cara mendial atau menelepon mobil tersebut untuk memasukan kata kunci didalam mobil tersebut agar bisa beroperasi.

\section{LANDASAN TEORI}

\section{Sistem Aktifasi}

Sistem aktifasi mobil ini bertujuan untuk aktifasi mobil menggunakan media suara yang berfungsi untuk meningkatkan pengamanan dilingkungan sekitar pemilik mobil ketika mobil ditinggal disuatu tempat yang jauh dari sang pemilik. sistem telepon difungsikan untuk menghindari terjadinya hal yang tidak diharapkan seperti pencurian. Contoh sistem keamanan mobil adalah:

- Voice Recognition

Sistem ini akan melakukan pengenalan suara yang terdapat pada memory untuk dibandingkan dengan suara yang sudah disimpan di modul Easy VR untuk aktifasi kunci kontak mobil dan kendali sistem mobil.

- Switch on

Sistem melakukan kendali terhadap pintu mobil ketika pintu terbuka tanpa membuka kunci. System akan mendial nomer yang dituju untuk memberitahukan kondisi yang terjadi.

- Remote motor

Sistem ini melakukan kendali terhadap motor untuk mengaktifkan maupun menonaktifkan.

\section{Easy Voice Recognition}

EasyVR adalah pengenalan suara yang dirancang untuk multi-tujuan yang dapat digunakan dengan semua host dengan antarmuka UART bertenaga di $3.3-5 \mathrm{~V}$, seperti tegangan pada papan Arduino. Beberapa contoh aplikasi termasuk smarthome, seperti cahaya yang dikendalikan oleh suara untuk switch kunci atau membuka pintu, atau menambahkan "pendengaran" untuk robot.
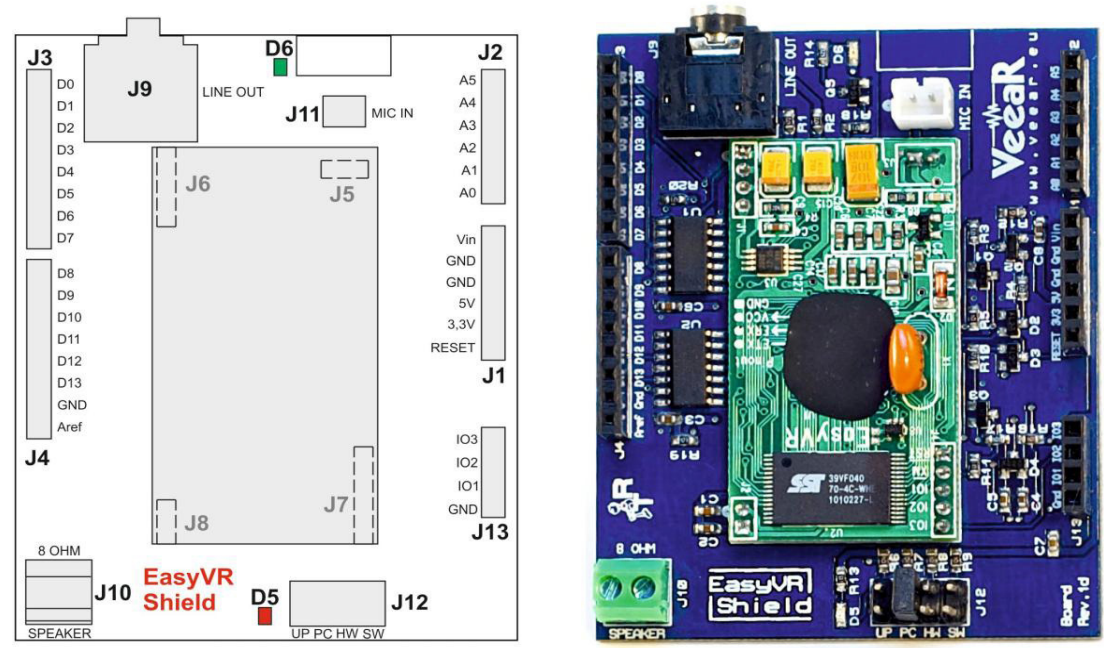

GAMBAR 1. Modul easy voice recognition.

\section{Software EasyVR}

Perangkat lunak EasyVR Commander dapat digunakan dengan mudah untuk mengkonfigurasi modul EasyVR agar dapat tersambung ke PC melalui papan adaptor, atau dengan menggunakan host board mikrokontroler dengan program "bridge" yang disediakan. didalam EasyVR Commander ini dapat ditentukan kelompok perintah atau password yang akan menghasilkan kode template dasar untuk dibandingkan nantinya. EasyVR Commander diperlukan untuk mengedit kode yang dihasilkan untuk mengimplementasikan logika aplikasi, tapi template berisi semua fungsi atau subrutin berfungsi untuk pengenalan suara 


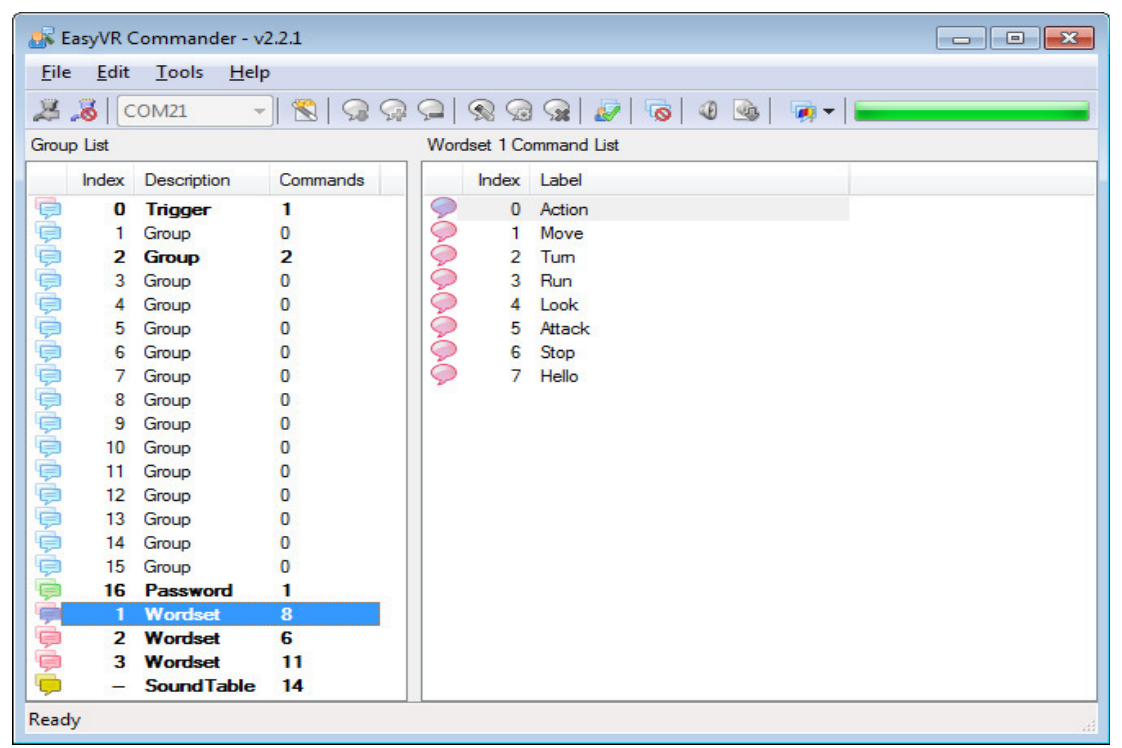

GAMBAR 2. Software EasyVR Commander

\section{PERANCANGAN SISTEM}

\section{Prinsip Kerja Sistem}

Berikut ini adalah prinsip kerja keseluruhan sistem yang digambarkan dalam blok diagram dibawah ini :

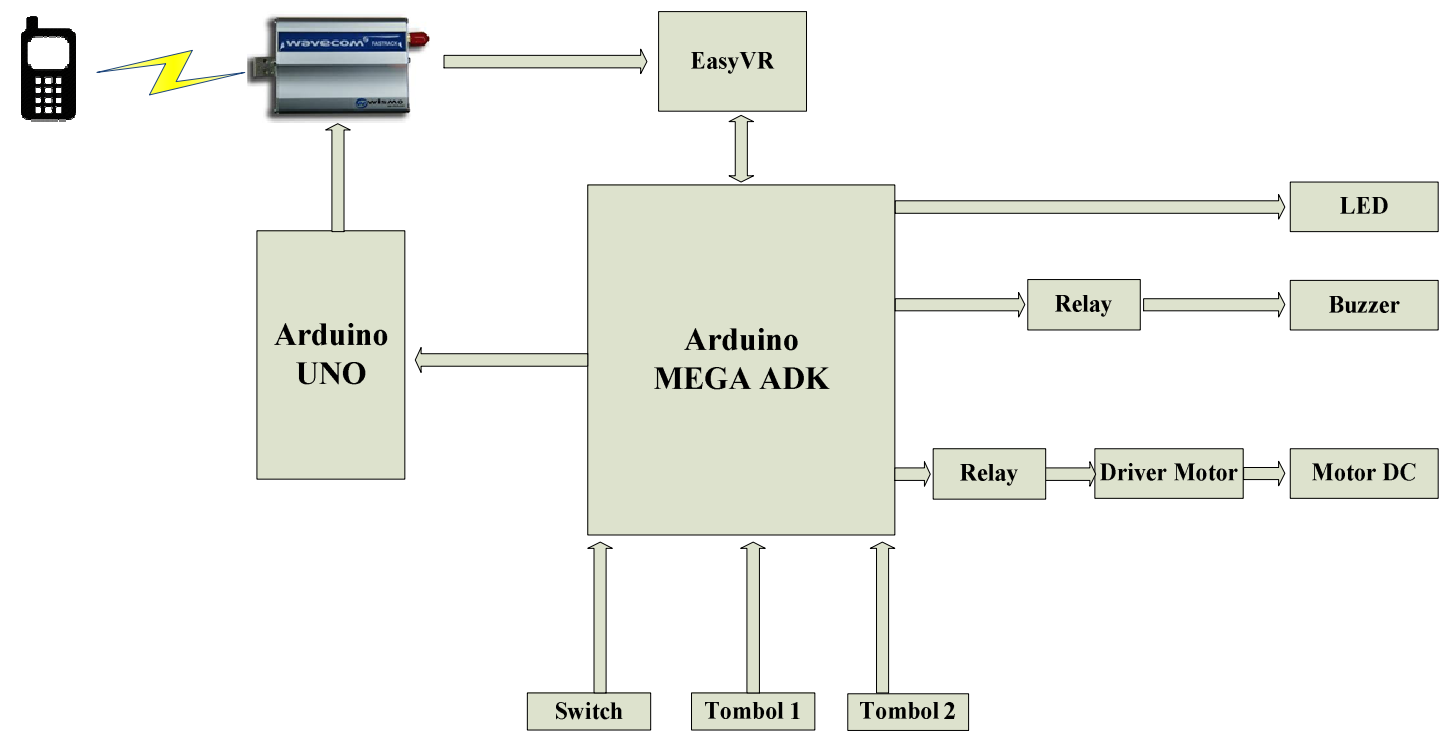

GAMBAR 3. Blok Diagram Sistem Keseluruhan

Pada perancangan sistem ini Mikrokontroler arduino ADK sebagai pusat pengatur dan pengendali seluruh perangkat pada sistem, serta arduino UNO sebagai pengatur dan pengolah sistem komunikasi untuk suara yang masuk. Seluruh perangkat pada sistem aplikasi aktifasi suara tersebut terintegrasi dengan modem GSM sebagai penghubung melalui jaringan telepon. Prinsip kerja dari sistem aplikasi ini digunakan sebagai aktifasi, security,andcontrolling pada mobil.aktifasimenggunakan suara yang sudah di simpan didalam sound table - sound table yang terdapat di dalam memori untuk dibandingkan dengan suara yang masuk. pada saat suara sudah dibandingkan dan cocok, arduino ADK akan memberi perintah untuk melakukan sesuatu sesuai dengan yang diperintahkan pemilik. Flowchart sistem arduino ADK dapat dilihat seperti terlihat pada gambar 4 dan 5 . 


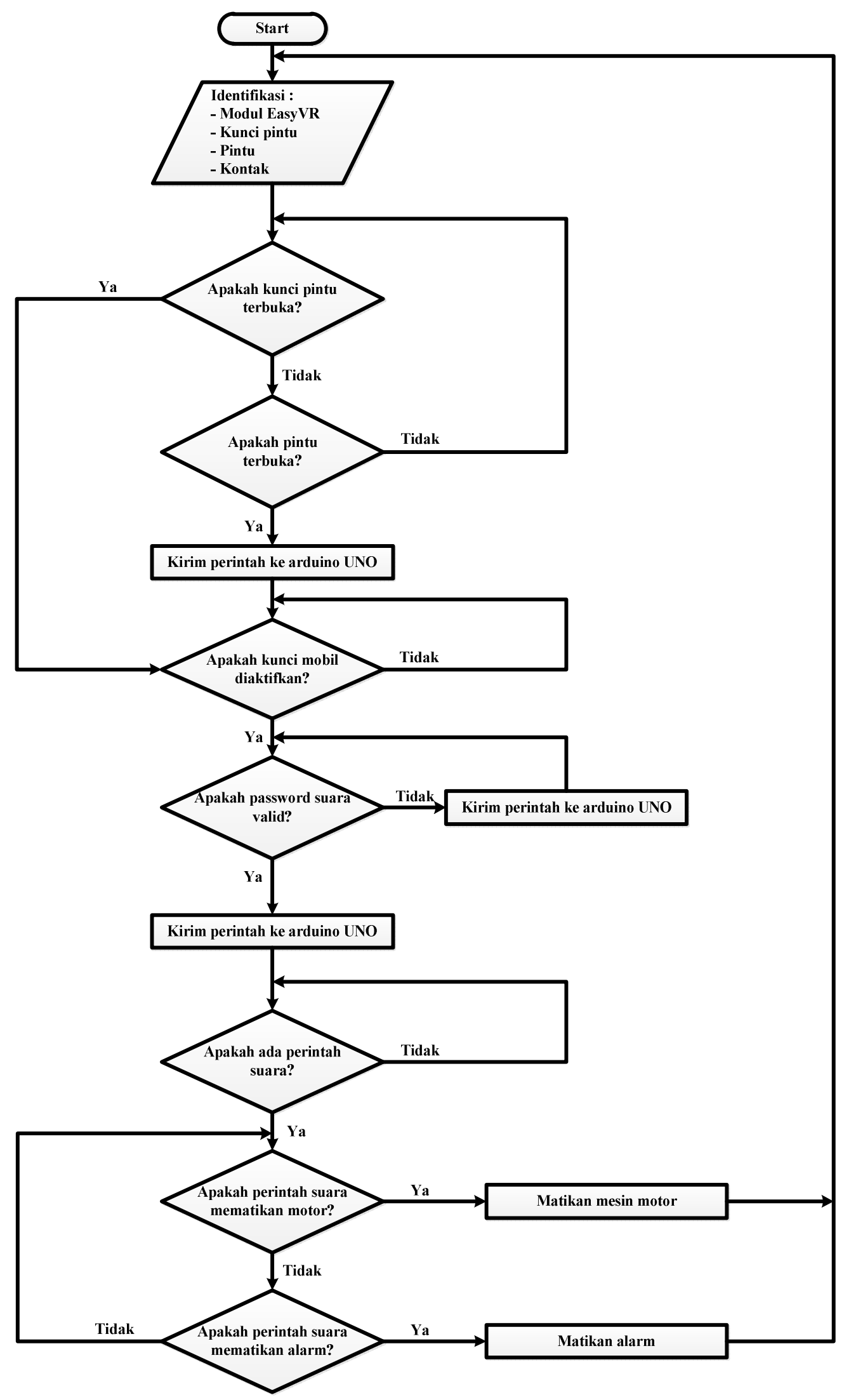

GAMBAR 4. Flowchart untuk sistem pada masukan arduino. 


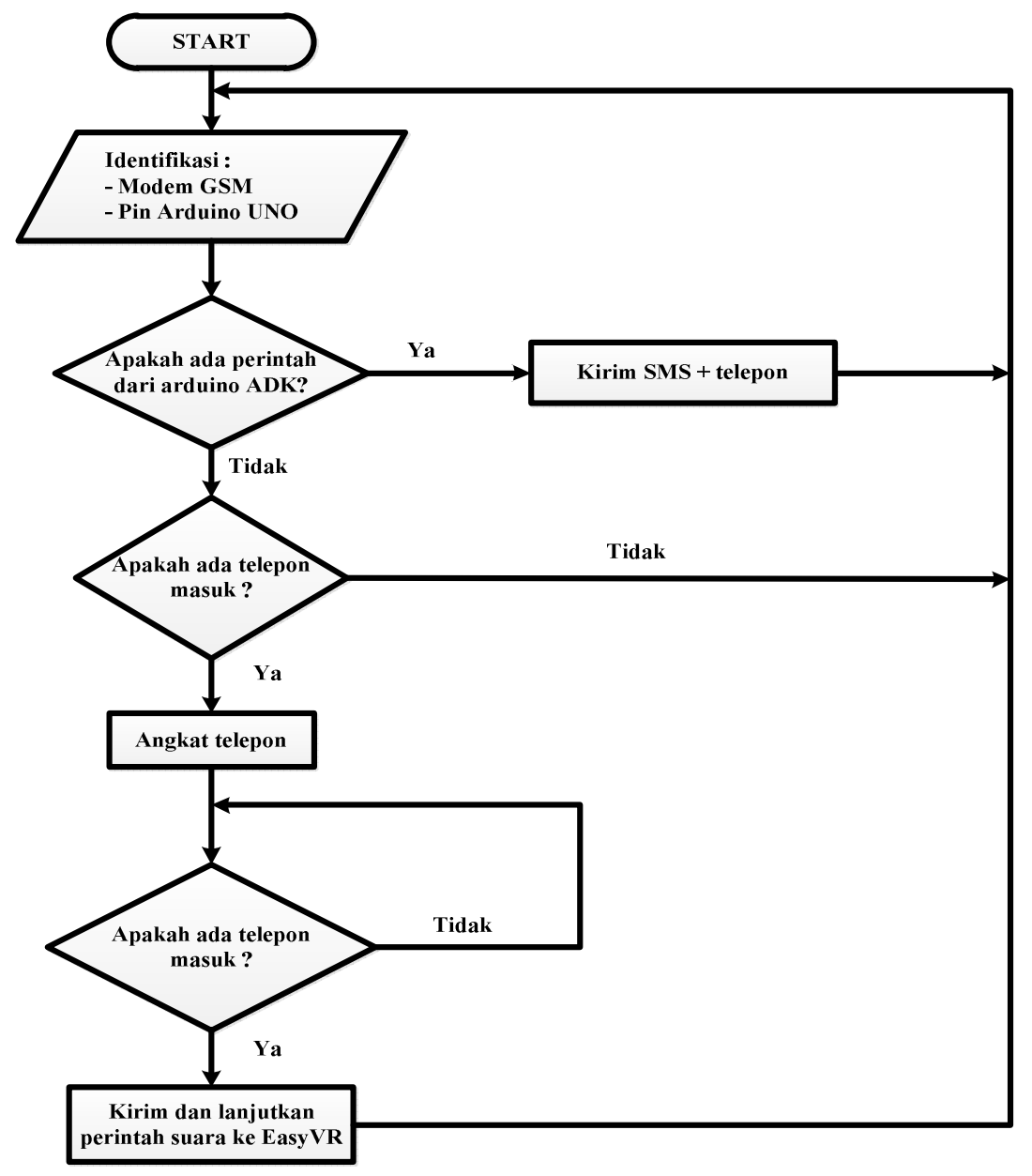

GAMBAR 5. Flowchart sistem pada mikrokontroler pada komunikasi seluler.

\section{Perancangan Hardware}

Mikrokontroler Arduino UNO digunakan sebagai brainware dari sistem pengontrolan komunikasi. Semua sistem komunikasi diatur oleh arduino UNO, data yang masuk dari arduino ADK akan diproses dan olah untuk nanti dilanjutkan dengan mengirimkan data perintah tersebut melaluli media modem GSM.

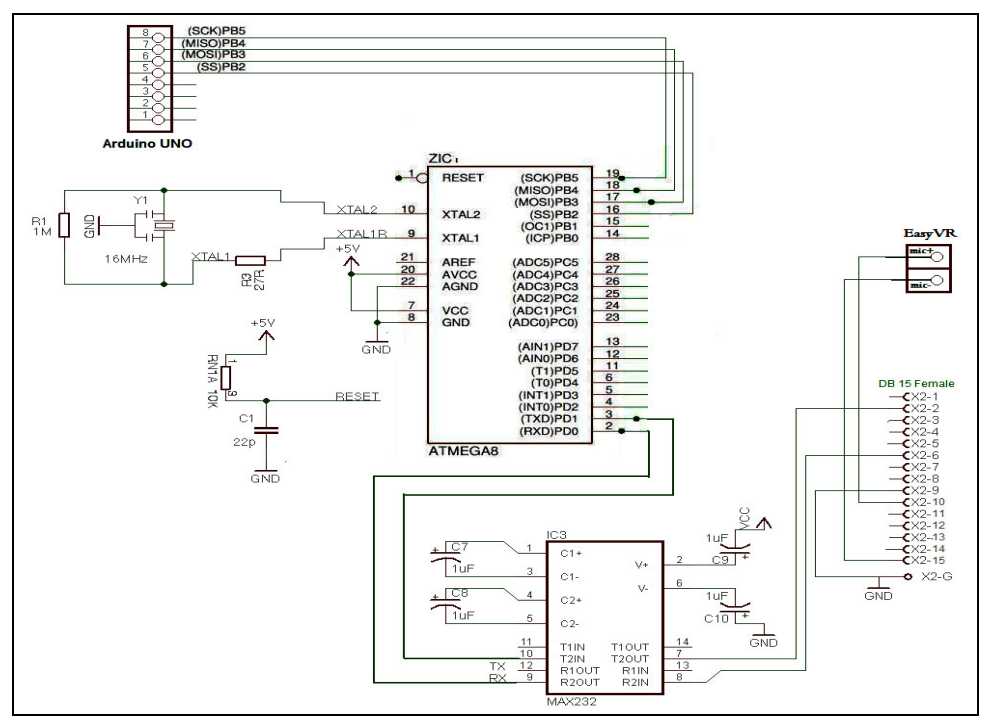

GAMBAR 6. Skematik pin mikrokontroler pada arduino UNO. 
Selanjutnya output dari wavecom berupa data suara akan diteruskan ke modul EasyVR yang akan digunakan sebagai data pembanding untuk menggerakan sistem keamanan mobil. Mikrokontroler arduino ADK digunakan sebagai sistem proses untuk kerja seluruh sistem keamanan pada mobil. Semua sistem keamanan pada mobil di atur oleh arduino ADK, mulai dari buzzer dan motor, modul EasyVR dan input yang berupa tombol - tombol dan switch. Sistem kerja arduino ADK disini ketika modul EasyVR mendapatkan data suara dari modem GSM yang kemudian dibandingkan dengan data suara yang ada pada sound tabel.

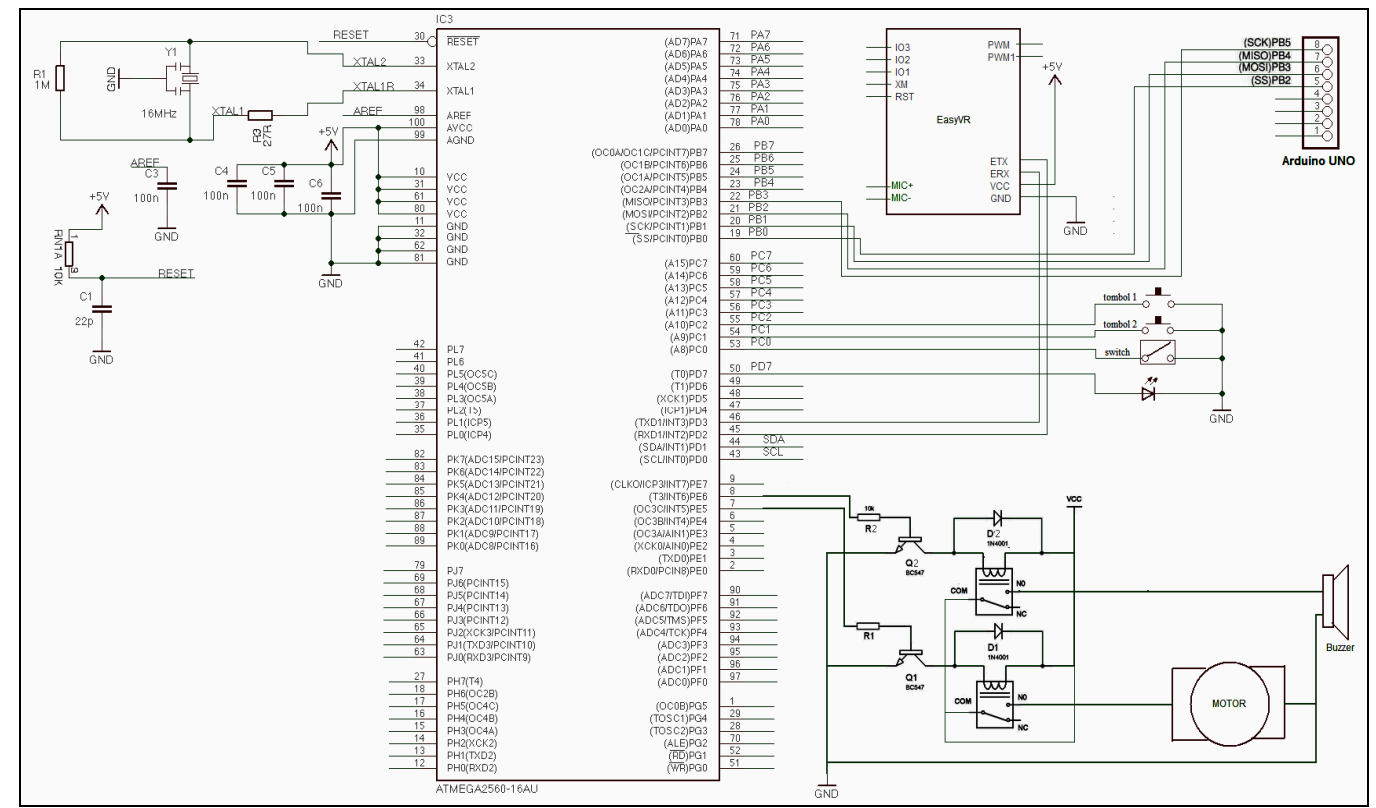

GAMBAR 7. Skematik pin mikrokontroller pada arduino ADK

\section{Perancangan Software Aplikasi keamanan mobil}

Prinsip kerja pada software ini adalah melakukan pemindaian dengan aktifasi suara dan juga pengontrolan terhadap motor dan Buzzer mobil yang menunjukan bahwa mobil itu dapat digunakan setelah mendapat perintah suara melalui telpon.EasyVR commander adalah program aplikasi sistem untuk memasukan suara yang diinginkan kedalam sound tabel yang terdapat pada voice recognition.

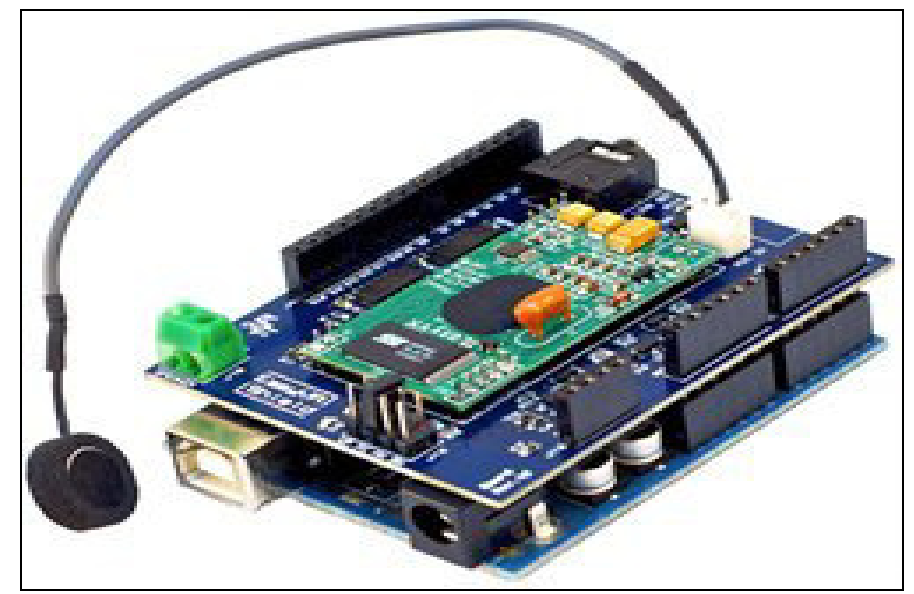

GAMBAR 8. Bentuk gabungan arduino dan easyVR

Hubungkan Arduino ADKdengan komputer dan menjalankan modul EasyVR Commander software. Perangkat lunak ini akan membuka seperti yang ditunjukkan pada gambar 9 . 


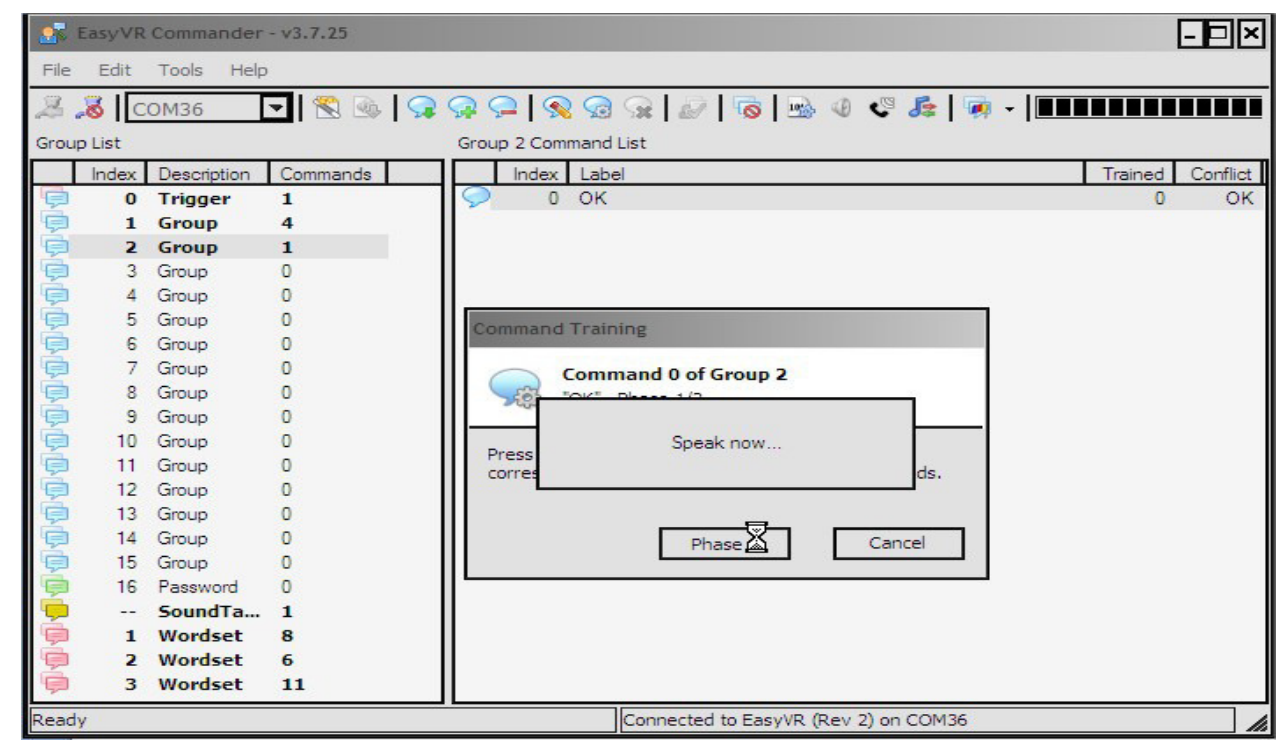

GAMBAR 9. Proses memasukan suarapada EasyVR commander

Software EasyVR diatas akan muncul ketika ingin memasukan suara perintah, sebuah kotak akan muncul yang mengatakan "berbicara sekarang", masukan perintah pada mic seperti yang di mau untuk direkam didalam EasyVR yang akan digunakan sebagai perbandingan kata kunci untuk aktifkan output sesuai kegunaan. Setelah diisi oleh perintah - perintah yang akan digunakan untuk mengendalikan sistem yang ada pada arduino ADK, EasyVR siap untuk digunakan sekarang setelah ditambahkan perintah. Pada gambar 10 adalah perintah untuk mengendalikan sistem yang ada pada arduino ADK.

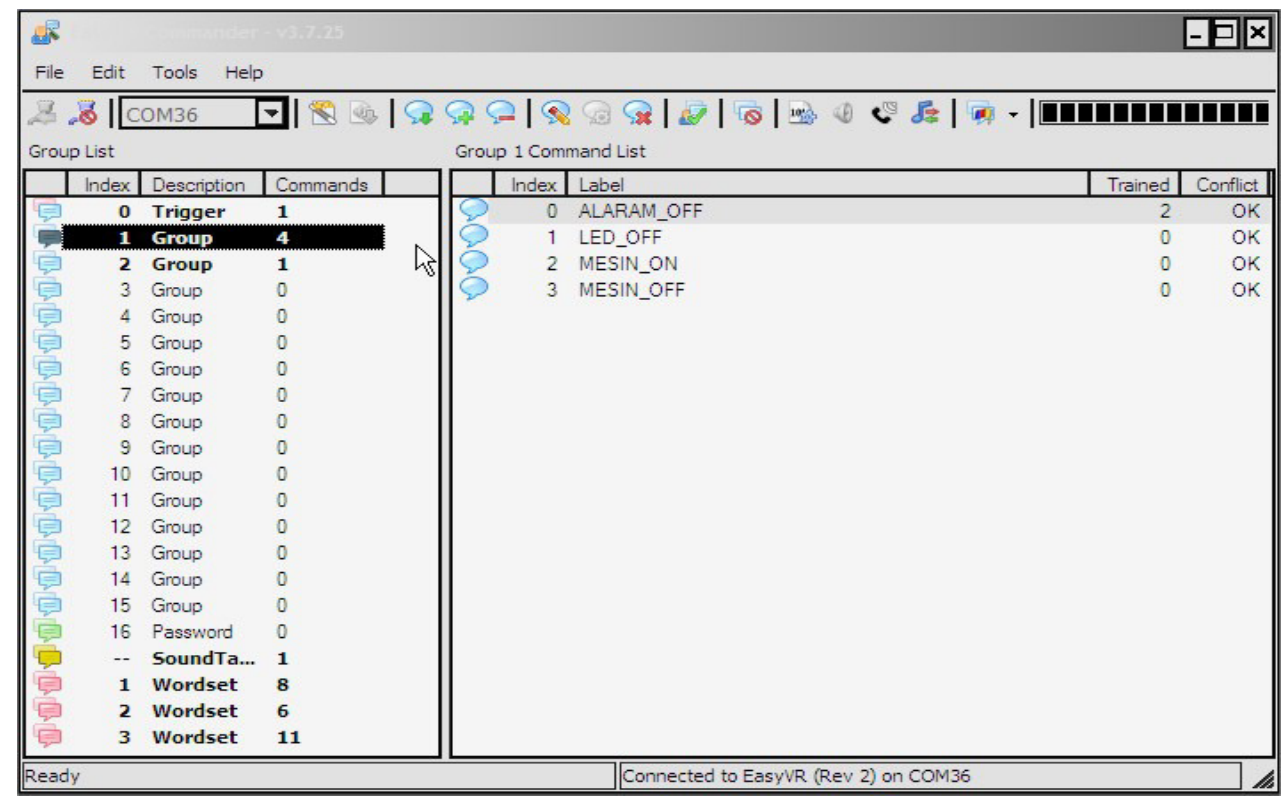

GAMBAR 10. Perintah suara pada EasyVR Commander

\section{PENGUJIAN SISTEM}

\section{Pegujian Pengiriman SMS dan Penerimaan Telepon}

Pengujian komunikasi ini menggunakan hyper terminal untuk membuktikan pengujian dan lama waktu pengiriman. Pada gambar dibawah ini di perlihatkan pengiriman SMS dari perangkat mobil ketika pintu mobil terbuka secara paksa dan penerimaan isi SMS dari perangkat mobil $t$ 


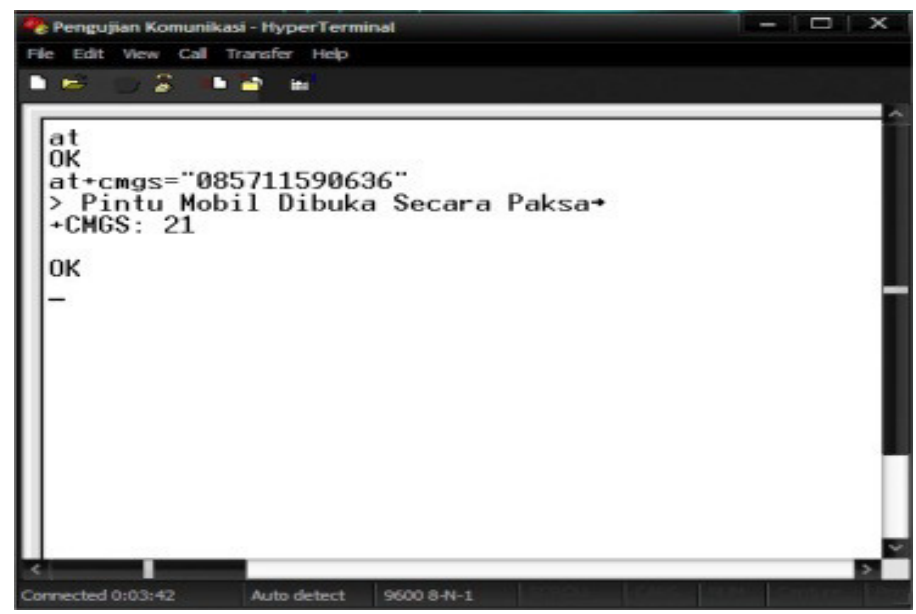

GAMBAR 11. Pengiriman sms pada hiperterminal

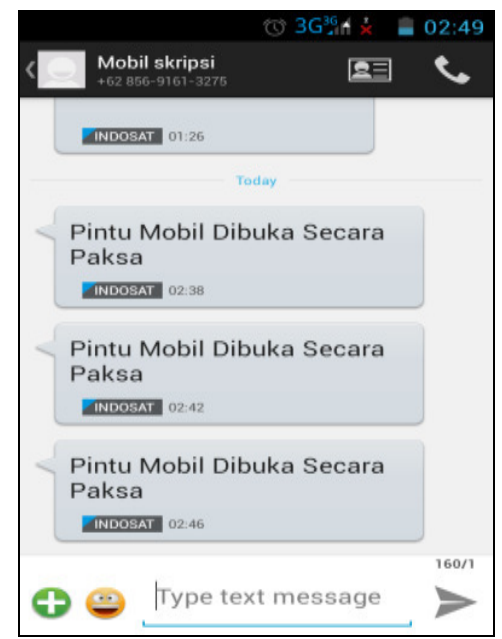

GAMBAR 12. Penerimaan sms pada Handphone.

Pengujian berikut ini dilakukan dengan tujuan apakah perangkat mobil dapat menerima telepon dari sang pemilik. fungsi telepon disini agar pemilik dapat memberikan aktifasi suara dan kendali perangkat mobil dengan menggunakan suara. hasil penerimaan telepon dibawahini menggunakan hyperterminal untuk pengujiannya :

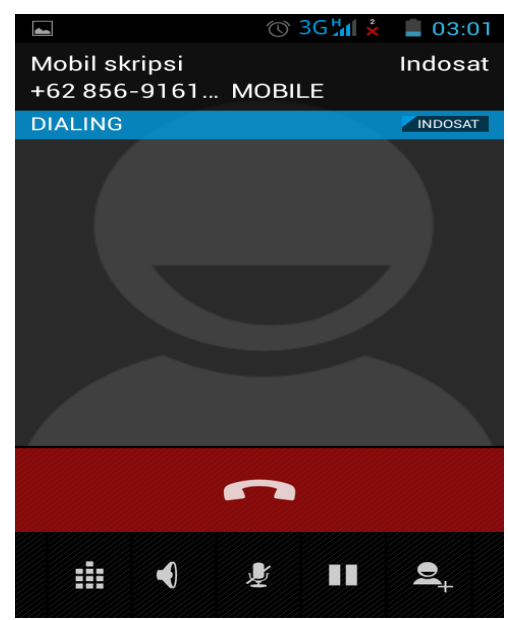

GAMBAR 13. Tampilan pada monitor hanphone dari pemilik mobil. 


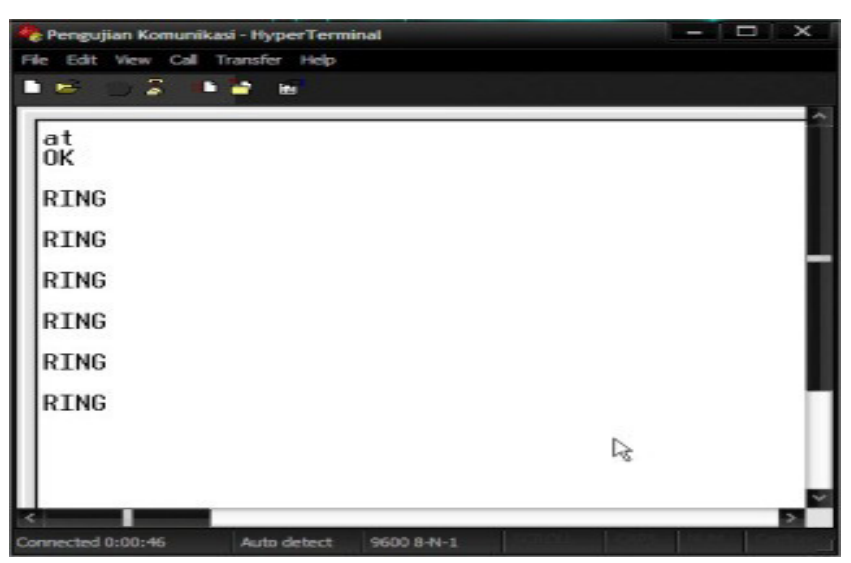

GAMBAR 14. Penerimaan telepon pada perangkat mobil

\section{Pengujian Respon Suara}

Dari kata-kata perintah yang ada di EasyVR, kita menguji salah satu kata yaitu MESIN_OFF. kata tersebut akan diuji oleh lima orang dalam kondisi yang berbeda-beda, yaitu :

- kondisi ketika lingkungan sekitar bising.

- kondisi ketika lingkungan sekitar tenang.

- kemiripan kata yang diucap.

- kondisi ketika hidung dalam keadaan tersumbat

a) Kondisi pengujian aktifasi suara pada kondisi bising dari kata MESIN_OFF :

\begin{tabular}{|l|l|l|l|l|l|l|}
\hline NO. & Pengujian Suara & Tes Ke-1 & Tes Ke-2 & Tes Ke-3 & Tes Ke-4 & Tes Ke-5 \\
\hline 1. & Ridha Alfian & Berhasil & Berhasil & Berhasil & Gagal & Berhasil \\
\hline 2. & Nasrul.D & Berhasil & Gagal & Gagal & Berhasil & Berhasil \\
\hline 3. & Miko Rizal & Berhasil & Berhasil & Gagal & Berhasil & Berhasil \\
\hline 4. & Yudha Sudarso & Gagal & Berhasil & Berhasil & Berhasil & Gagal \\
\hline 5. & Rudy & Gagal & Berhasil & Berhasil & Berhasil & Berhasil \\
\hline Hasil Pengujian & $60 \%$ & $80 \%$ & $60 \%$ & $80 \%$ & $80 \%$ \\
\hline
\end{tabular}

b) Kondisi pengujian aktifasi suara pada kondisi keadaan normal atau hening dari kata MESIN_OFF :

\begin{tabular}{|l|l|l|l|l|l|l|}
\hline NO. & Pengujian Suara & Tes Ke-1 & Tes Ke-2 & Tes Ke-3 & Tes Ke-4 & Tes Ke-5 \\
\hline 1. & Ridha Alfian & Berhasil & Berhasil & Berhasil & Berhasil & Berhasil \\
\hline 2. & Nasrul.D & Berhasil & Berhasil & Berhasil & Berhasil & Berhasil \\
\hline 3. & Miko Rizal & Berhasil & Berhasil & Gagal & Berhasil & Berhasil \\
\hline 4. & Yudha Sudarso & Berhasil & Berhasil & Berhasil & Berhasil & Berhasil \\
\hline 5. & Rudy & Berhasil & Berhasil & Berhasil & Berhasil & Berhasil \\
\hline Hasil Pengujian & $100 \%$ & $\mathbf{1 0 0} \%$ & $\mathbf{8 0} \%$ & $100 \%$ & $\mathbf{1 0 0 \%}$ \\
\hline
\end{tabular}

c) Kondisi pengujian aktifasi suara pada kata MESIN_OFF yang diucapkan berupa kata RESIN_OFF : 


\begin{tabular}{|l|l|l|l|l|l|l|}
\hline NO. & Pengujian Suara & Tes Ke-1 & Tes Ke-2 & Tes Ke-3 & Tes Ke-4 & Tes Ke-5 \\
\hline 1. & Ridha Alfian & Berhasil & Gagal & Berhasil & Berhasil & Berhasil \\
\hline 2. & Nasrul.D & Berhasil & Berhasil & Gagal & Gagal & Berhasil \\
\hline 3. & Miko Rizal & Gagal & Berhasil & Gagal & Gagal & Gagal \\
\hline 4. & Yudha Sudarso & Berhasil & Gagal & Berhasil & Berhasil & Berhasil \\
\hline 5. & Rudy & Berhasil & Berhasil & Berhasil & Gagal & Gagal \\
\hline Hasil Pengujian & $80 \%$ & $60 \%$ & $60 \%$ & $60 \%$ & $80 \%$ \\
\hline
\end{tabular}

d) Kondisi pengujian terakhir ketika aktifasi suara pada kondisi keadaan suara tidak normal (disimulasikan dengan kondisi hidung ditutup) dari kata MESIN_OFF :

\begin{tabular}{|l|l|l|l|l|l|l|}
\hline NO. & Pengujian Suara & Tes Ke-1 & Tes Ke-2 & Tes Ke-3 & Tes Ke-4 & Tes Ke-5 \\
\hline 1. & Ridha Alfian & Berhasil & Berhasil & Berhasil & Berhasil & Berhasil \\
\hline 2. & Nasrul.D & Berhasil & Berhasil & Gagal & Berhasil & Berhasil \\
\hline 3. & Miko Rizal & Berhasil & Gagal & Berhasil & Gagal & Berhasil \\
\hline 4. & Yudha Sudarso & Berhasil & Berhasil & Berhasil & Berhasil & Berhasil \\
\hline 5. & Rudy & Berhasil & Berhasil & Berhasil & Berhasil & Berhasil \\
\hline Hasil Pengujian & $100 \%$ & $80 \%$ & $80 \%$ & $80 \%$ & $100 \%$ \\
\hline
\end{tabular}

\section{Pengujian Fungsi Alat}

Kondisi pengujian alat disini dilakukan dengan menempatkan mobil diruang terbuka ketika tidak ada pengalangan sehingga dapat diketahuiapakah kondisialat tersebut aktif atau tidak bila dimasukan aktifasi suara :

\begin{tabular}{|l|l|l|l|l|}
\hline NO. & Pengujian Suara & Aktifkan Motor & Nonaktif Motor & Nonaktif Alaram \\
\hline 1. & Percobaan ke-1 & Berhasil & Berhasil & Berhasil \\
\hline 2. & Percobaan ke-2 & Berhasil & Gagal & Berhasil \\
\hline 3. & Percobaan ke-3 & Berhasil & Berhasil & Berhasil \\
\hline 4. & Percobaan ke-4 & Berhasil & Berhasil & Berhasil \\
\hline 5. & Percobaan ke-5 & Berhasil & Berhasil & Berhasil \\
\hline 6. & Percobaan ke-6 & Berhasil & Berhasil & Berhasil \\
\hline 7. & Percobaan ke-7 & Berhasil & Berhasil & Berhasil \\
\hline 8. & Percobaan ke-8 & Berhasil & Berhasil & Gagal \\
\hline 9. & Percobaan ke-9 & Gagal & Berhasil & Berhasil \\
\hline 10. & Percobaan ke-10 & Berhasil & Berhasil & Berhasil \\
\hline \multicolumn{2}{|l|}{ Hasil Pengujian } & $90 \%$ & $90 \%$ & $100 \%$ \\
\hline
\end{tabular}

Kondisi pengujian alat disini dilakukan dengan menempatkan mobil diruang tertutup atau berada dalam ruangan. Untuk mengetahui kondisi apakah alat tersebut aktif atau tidak bila dimasukan aktifasi suara : 


\begin{tabular}{|l|l|l|l|l|}
\hline NO. & Pengujian Suara & Aktifkan Motor & Nonaktif Motor & Nonaktif Alaram \\
\hline 1. & Percobaan ke-1 & Gagal & Berhasil & Gagal \\
\hline 2. & Percobaan ke-2 & Berhasil & Berhasil & Berhasil \\
\hline 3. & Percobaan ke-3 & Gagal & Berhasil & Berhasil \\
\hline 4. & Percobaan ke-4 & Berhasil & Berhasil & Berhasil \\
\hline 5. & Percobaan ke-5 & Berhasil & Berhasil & Gagal \\
\hline 6. & Percobaan ke-6 & Berhasil & Gagal & Berhasil \\
\hline 7. & Percobaan ke-7 & Berhasil & Gagal & Berhasil \\
\hline 8. & Percobaan ke-8 & Berhasil & Berhasil & Berhasil \\
\hline 9. & Percobaan ke-9 & Berhasil & Gagal & Gagal \\
\hline 10. & Percobaan ke-10 & Berhasil & Berhasil & Berhasil \\
\hline Hasil Pengujian & $\mathbf{8 0} \%$ & $\mathbf{7 0} \%$ & $\mathbf{7 0} \%$ \\
\hline
\end{tabular}

\section{KESIMPULAN}

Hasil dari empat pengujian diatas yang berupa kata MESIN_OFF yang didasarkan pada kondisi yang berbeda - beda untuk mengetahui tingkat kehandalan sistem yang dibuat adalah pada kondisi lingkungan yang bising tingkat keberhasilan $72 \%$, pada kondisi lingkungan yang normal atau hening tingkat keberhasilan 96\%, pada kondisi dimana kata MESIN_OFF diucapkan menjadi RESIN_OFFtingkat keberhasilan 68\% sedangkan pada kondisi dimana disimulasikan bahwa suara sedang tidal normaltingkat keberhasilan 88\%. Hasil dari dua pengujian aktifasi alat dengan media suara yang didasarkan pada kondisi tertutup dan kondisi ruang lingkup terbuka, didapat hasil pengujian dari kondisi ketika berada diruangan terbuka untuk menonaktifkan alaram sebesar $90 \%$ untuk akif motor, $90 \%$ untuk menonaktifkan motor dan $100 \%$ untuk menonaktifkan alaram. Sementara hasil pengujian dari kondisi ketika berada diruangan tertutup untuk untuk menonaktifkan alaram sebesar $80 \%$ untuk akif motor, $70 \%$ untuk menonaktifkan motor dan $70 \%$ untuk menonaktifkan alarm.

\section{DAFTAR PUSTAKA}

[1] Arduino Uno board, "Based on the ATmega328(datasheet)", http://arduino.cc/en/Main/ArduinoBoardUno, 24.03.2014.

[2] Arduino ADK board,"Based on the ATmega2560 MEGA ADK (datasheet)", http://arduino.cc/en/Main/ArduinoBoardUno, 24.03.2014.

[3] Atmel Corporation, "8-bit Microcontroller with 4K Bytes In-System Programmable Flash", http://www.atmel.com/Images/doc2487.pdf,2008, 05.04.2014.

[4] EasyVR Shield, "Based on the EasyVR ( datasheet )", http://www.veear.eu.pdf, 2008, 11.04.2014.

[5] S. Schuster, R. "Speech control with the EasyVR Shield", http://www.zipfelmaus.com/blog/ arduino-speech-control-easyvr-shield/, 11.04.2014.

[6] Nathan Chantrell. "SMS with the Wavecom WMOi3 GSM Modem and Arduino", http://nathan.chantrell.net/20130604/sms-with-the-wavecom-wmoi3-gsm-modem-andarduino/, June 4, 2013 Copyright (C) 1995-2014, 13.05.2014.

[7] Nick Gammon. "SPI - Serial Peripheral Interface - for Arduino", http://www.gammon.com.au/forum/?id=10892, 25.06.2014. 